\title{
PARADIGMA POLITIK ISLAM: PROTOTIPE NEGARA MADINAH DAN PRINSIP-PRINSIP POLITIK KENEGARAAN
}

\author{
Efrinaldi \\ Fakultas Syariah IAIN Imam Bonjol Padang \\ Jl. Gelugur Blok L No. 8 Wisma Indah II Lapai, Padang, Sumatera Barat \\ E-mail: Efrinaldi_74@yaho0.co.id.
}

\begin{abstract}
In the history of Islamic politics, the leadership of the Messenger of Allah in Medina, who is protecting heterogeneous citizens, is a proof of the exisitency of the state and government in Islam. The Leadership of the Apostles in Medina indicates the fulfillment of the nominal requirements as a state. In the Medina state he is recognized as the supreme leader, which means the holder of the legislative, executive and judicial powers. In practice, however, he delegated executive and judicial duties to his capable and capable companions. In essence, there are two references to the life of the state arranged in the Medina Charter, namely: 1) All followers of Islam is a people although they are different tribes; 2) The relationship between Muslim and non-Muslim communities is based on the principles of: (a) being good neighbors, (b) helping each other against common enemies, (c) defending persecuted, (d) advising each other, and (e) respecting freedom religion. The essential elements for the formation of the State of Medina, consisting of a region, namely Medina; people composed of Muslim and non-Muslim groups; the government is controlled by the Prophet and assisted by his companions; as well as sovereigns based on the written law (Medina Charter) within the community of Medina.
\end{abstract}

Keywords: Islamic politics, Medina Charter, state politics

\begin{abstract}
Abstrak: Dalam sejarah politik Islam, kepemimpinan Rasulullah saw di Madinah yang mengayomi warga yang heterogen, menjadi bukti eksisitensi negara dan pemerintahan dalam Islam. Kepemimpinan Rasul di Madinah menunjukkan telah terpenuhinya syarat-syarat nominal sebagai suatu negara. Dalam negara Madinah beliau diakui sebagai pemimpin tertinggi, yang berarti pemegang kekuasaan legislatif, eksekutif dan yudikatif. Namun, dalam prakteknya beliau mendelegasikan tugas-tugas eksekutif dan yudikatif kepada para sahabat yang dianggap cakap dan mampu. Pada pokoknya, ada dua acuan bagi kehidupan bernegara yang diatur dalam Piagam Madinah, yaitu: 1) Semua pemeluk Islam adalah satu umat walaupun mereka berbeda suku; 2) Hubungan antara komunitas Muslim dan non-Muslim berdasarkan pada prinsip: (a) bertetangga baik, (b) saling membantu dalam menghadapi musuh bersama, (c) membela mereka yang teraniaya, (d) saling menasehati, dan (e) menghormati kebebasan agama. Unsur-unsur penting bagi terbentuknya Negara Madinah, terdiri dari adanya wilayah, yaitu Madinah; rakyat yang terdiri dari golongan-golongan Muslim dan non-Muslim; pemerintahan dikendalikan oleh Nabi saw dan dibantu oleh para sahabatnya; serta berdaulat yang berdasarkan pada undang-undang tertulis (Piagam Madinah) dalam komunitas masyarakat Madinah tersebut.
\end{abstract}

Kata kunci: politik Islam, Piagam Madinah, politik kenegaraan 


\section{Pendahuluan}

Dalam teori politik Islam, keberadaan negara itu amat penting artinya dalam rangka mengimplementasikan syariat Islam. Eksistensi negara untuk menegakkan keadilan, mewujudkan kesejahteraan rakyat, memelihara persatuan umat lewat kerjasama dan tolong-menolong, dan menciptakan keamanan dan ketenangan. Menurut Ibn Abi Rabi', "Negara itu bertujuan untuk memelihara dan melaksanakan peraturan-peraturan serta kewajiban-kewajiban yang diletakkan oleh Allah dan Rasul-Nya."2 Al-Baqillani (w. 403 H/1013 M) menegaskan keberadaan negara dan pemerintahan itu dibentuk untuk menegakkan hukum yang telah ditetapkan, membela umat dari gangguan musuh, melenyapkan penindasan, dan menghilangkan keresahan masyarakat, memeratakan penghasilan negara bagi rakyat dan syariat yang dibebankan kepadanya. Singkatnya, segala sesuatu yang berkaitan dengan kepentingan umum harus sesuai dengan syariat. ${ }^{3}$

Pemikiran tersebut memperlihatkan betapa keberadaan negara secara mendasar sangat urgen untuk mewujudkan kebahagiaan dan kesejahteraan rakyat demi tercapainya masyarakat adil dan makmur, yang dalam teori politik Islam, dilandasi pada nilai-nilai religius karena sebagai alat untuk melaksanakan syariat Islam.

Dalam sejarah politik Islam, kepemimpinan Rasulullah saw di Madinah yang mengayomi warga yang heterogen menjadi arti penting tentang eksisitensi negara dan pemerintahan dalam Islam. Kepemimpinan Rasul di Madinah menjadi buktibukti bagi terpenuhinya syarat-syarat nominal untuk disebut sebagai suatu "negara".

Unsur-unsur penting bagi terbentuknya Negara Madinah, dapat dikemukakan, terdiri dari adanya wilayah, yaitu Madinah; rakyat yang terdiri dari golongan-golongan Muslim dan non-Muslim; pemerintahan dikendalikan oleh Nabi saw dan

\footnotetext{
${ }^{1}$ Ibn Abi Rabi' adalah teoritisi politik Islam yang hidup pada masa pemerintahan Khalifah al-Mu’tashim (833-842 M) era Dinasti Abbasiyah.

2 Syihab al-Din Ahmad bin Muhammad bin Abi Rabi', Suluk al-Malik fi Tadbir al-Mamalik, (Kairo: Dar al-Sya’ab, 1970), h. 102.

${ }^{3}$ Lihat: Lambton, Ann K.S., State and Government in Medieval Islam, (London: Oxford University Press, 1981), h. 73-76.
}

dibantu oleh para sahabatnya; serta berdaulat yang berdasarkan pada undang-undang tertulis (Piagam Madinah) dalam komunitas masyarakat Madinah tersebut. Kajian tentang karakteristik Negara Madinah dan prinsip-prinsip politik kenegaraan menjadi fokus bahasan dalam tulisan ini.

\section{Prototipe Negara Madinah: Cikal-Bakal Pembentukan Negara dalam Islam}

Ketika Nabi Muhammad saw sampai di Madinah, beliau dihadapkan pada persoalan bagaimana menata masyarakat yang kompleks. Pada waktu itu penduduk Madinah terdiri dari: 1) Muslim pendatang dari Mekkah; 2) Muslim Madinah (kaum Anshar) yang terdiri atas suku Aus dan Khazraj; 3) Anggota suku Aus dan Khazraj yang masih menyembah berhala, sebagian kemudian masuk Islam; 4) Orang-orang Yahudi yang terbagi dalam tiga suku utama: bani Qainuqa', bani Nazhir, bani Quraizhi; serta subsuku yang lain. ${ }^{4}$

Untuk menata kehidupan sosial-politik komunitas di Madinah yang kompleks tersebut, Nabi menempuh dua cara. Pertama, menata interen kehidupan kaum Muslim, yaitu mempersaudarakan antara kaum Muhajirin dan kaum Anshar secara efektif. ${ }^{5}$ Persaudaraan ini bukan diikat oleh hubungan darah dan kabilah, melainkan atas dasar ikatan iman. Inilah merupakan awal terbentuknya komunitas Islam untuk pertama kali. Philip K. Hitti menyebutnya sebagai "suatu miniatur dunia Islam". 6 Kedua, Nabi mempersatukan antara kaum Muslim dan kaum Yahudi bersama sekutu-sekutunya.

Di Madinah, sebagai tempat yang dipilih Nabi untuk menetap setelah hijrah dari Mekah pada tahun 622 M, ${ }^{7}$ Nabi sebenarnya menempati suatu posisi yang unik, yaitu sebagai pemimpin dan sumber spritual undang-undang ketuhanan, namun

${ }^{4}$ Moh. Zafrullah Khan, Muhammad Seal of the Prophet, (London: Routledge and Kegan Paul, 1980), h. 88.

${ }^{5}$ Ibn Hisyam, Sirah al-Nabawiyah, (Beirut: Mathba'ah Muhammad Ali Shabih, t.t.), j.1, h. 303-305.

${ }^{6}$ Philip K.Hitti, Capital Cities of Arab Islam, (Minneapolis: University of Minnesota, 1973), h. 35.

${ }^{7}$ Peristiwa hijrah ini, versi Thomas W.Arnold, dinilai sebagai “suatu gerakan strategi yang jitu,” karena hal ini bertujuan untuk menyelamatkan kaum Muslimin agar terbebas dari tindakan sewenang-wenang kaum Quraisy.” (Thomas W. Arnold, The Caliphate, (London: Routledge and Kegan Paul Ltd.,1965), h. 23. 
sekaligus juga pemimpin pemerintahan Islam yang pertama. ${ }^{8}$ Dalam Negara Madinah itu, tegas Thomas W. Arnold, "Dalam waktu yang bersamaan Nabi adalah sebagai pemimpin agama dan kepala negara."”

Atas dasar itu, terbentuknya masyarakat keagamaan di Madinah yang bukan berdasarkan ikatan darah membawa kepada terbentuknya Negara Madinah. Terbentuknya Negara Madinah ini, sebenarnya merupakan akibat dari perkembangan penganut Islam yang menjelma menjadi kelompok sosial dan memiliki kekuatan riil pada pasca periode Mekah di bawah pimpinan Nabi.

Kepemimpinan Nabi selaku kepala negara itu bertujuan untuk mengatur segala persoalan dan memikirkan kemaslahatan umat secara keseluruhan, dalam rangka pelaksanaan siyasah syar'iyah. Kapasitas Muhammad saw sebagai kepala negara dapat dibuktikan dengan tugastugas yang beliau lakukan. Beliau mempersatukan penduduk Madinah yang heterogen yang mencegah timbulnya konflik-konflik di antara mereka agar terjamin ketertiban intern. Beliau mengadakan perjanjian damai dengan tetangga agar terjamin ketertiban ekstern, menjamin kebebasan bagi semua golongan, mengorganisir militer dan memimpin peperangan, melaksanakan hukum bagi pelanggar hukum, menerima perutusan dari berbagai suku Arab di Jazirah Arab, mengirim surat-surat dan delegasi kepada para penguasa di Jazirah Arab, mengeluarkan zakat dan pajak serta larangan riba di bidang ekonomi untuk menjembatani jurang pemisah antara golongan kaya dan miskin, menjadi hakam (arbiter) dalam menyelesaikan perbedaan pendapat dan perselisihan, menunjuk para sahabat untuk menjadi wali dan hakim-hakim di daerahdaerah, melaksanakan musyawarah dan sebagainya.

Ditinjau dari dimensi ilmu politik dan tatanegara, aktifitas Rasul di Madinah itu mencuat dengan term "tugas-tugas atau fungsi pemerintahan". Tugas-tugas pemerintah itu, dalam visi ilmu politik adalah untuk mencapai tujuan negara dengan melaksanakan

${ }^{8}$ Harun Nasution, Islam Ditinjau dari Berbagai Aspeknya, (Jakarta: UI Press, 1985), j.1,h.92.

9 Thomas W.Arnold, Loc.Cit. dan Philip K.Hitti, History of the Arabs, (London: The Macmillan Press Ltd., 1970), h.120-121 penertiban dan mencegah bentrokan-bentrokan dalam masyarakat, mengusahakan kesejahteraan dan kemakmuran rakyat, mewujudkan pertahanan dan penegakkan keadilan ${ }^{10}$. Dalam sumber lain ditandaskan bahwa tugas-tugas kepala negara atau pemerintah dengan aparaturnya adalah mengurus negara dan memimpin seluruh rakyat dalam berbagai aspek kehidupan, mempertahankan kemerdekaan, melaksanakan keamanan dan ketertiban umum agar terhindar dari gangguan dan serangan dari luar maupun dari dalam, mengembangkan segala sumber bagi kepentingan hidup bangsa dalam bidang-bidang sosial, politik, ekonomi dan kebudayaan. ${ }^{11}$

Tugas pemerintahan lainnya yang dilakukan Muhammad saw sebagai kapala negara tampak tidak terpusat pada diri beliau. Dalam negara Madinah beliau diakui sebagai pemimpin tertinggi, yang berarti pemegang kekuasaan legislatif, eksekutif dan yudikatif. Tapi, walaupun pada masa itu orang belum mengenal teori pemisahan dan pembagian kekuasaan, namun dalam prakteknya beliau mendelegasikan tugas-tugas eksekutif dan yudikatif kepada para sahabat yang dianggap cakap dan mampu.

Timbulnya berbagai masalah yang dihadapi dan perkembangan wilayah kekuasaan menuntut adanya peta perkembangan tugas. Untuk pemerintahan di Madinah Nabi menunjuk beberapa sahabat sebagai pembantu beliau, sebagai katib (sekretaris), sebagai 'amil (pengelola zakat), dan sebagai qadhi (hakim). ${ }^{12}$

Dalam pranata sosial di bidang ekonomi yang juga menjadi bagian tugas kenegaraan, Nabi Muhammad saw berusaha mewujudkan keadilan dan kesejahteraan sosial rakyat Madinah. Untuk tujuan itu beliau mengelola zakat, infaq, shadaqah yang berasal dari kaum Muslim, ghanimah yaitu harta rampasan perang dan jizyah ${ }^{13}$ yang berasal

${ }^{10}$ Miriam Budiardjo, Dasar-dasar Ilmu Politik, (Jakarta: Gramedia, 1997), h. 46

${ }^{11}$ G.S. Diponolo, Ilmu Negara, (Jakarta: Balai Pustaka, 1975), jilid 1, h. 55

${ }^{12}$ Dalam sejarah, misalnya, Muadz Ibn Jabal, dikenal sebagai hakim (qadhi) yang ditugaskan Nabi ke negeri Yaman.

${ }^{13}$ Jizyah oleh kalangan juris Islam disebut juga "pajak perlindungan" (protection tax). Lihat: Said Ramadhan, Islamic Law: Its Scope and Equity, $2^{\text {nd }}$ Edition 1970, h. 134 
dari warga negara non-Muslim.

Dari sebagian contoh praktek pemerintah yang dilakukan Muhammad saw tersebut, tampak beliau dalam kapasitasnya sebagai kepala negara dalam memerintah Negara Madinah dapat dikatakan amat demokratis. Beliau tidak bertindak otoriter sekalipun itu sangat mungkin beliau lakukan dan akan dipatuhi oleh umat Islam mengingat statusnya sebagai Rasul Allah yang wajib ditaati. Kerangka kerja konstitusional pemerintahan di Madinah ini kemudian tertera dalam sebuah dokumen terkenal yang disebut dengan "Konstitusi Madinah" atau "Piagam Madinah". ${ }^{14}$

Pada pokoknya, ada dua acuan bagi kehidupan bernegara yang diatur dalam Piagam Madinah, yaitu: 1) Semua pemeluk Islam adalah satu umat walaupun mereka berbeda suku; 2) Hubungan antara komunitas Muslim dan non-Muslim berdasarkan pada prinsip: (a) bertetangga baik, (b) saling membantu dalam menghadapi musuh bersama, (c) membela mereka yang teraniaya, (d) saling menasehati, dan (e) menghormati kebebasan agama.

Tentang Piagam Madinah ini, Ahmad Ibrahim Syarif mengatakan:

Hampir belumlah kita mengenal sebelumnya adanya suatu negara yang semenjak berdirinya diumumkan dengan (suatu proklamasi) di dalam konstitusi negara tertulis, sebagai halnya negara Islam. Piagam ini sangatlah penting untuk memahami bentuk negara Islam. Begitu juga ia penting untuk memahami segala peristiwa yang timbul silih berganti sesudah demikian. ${ }^{15}$

Secara sosiologis piagam tersebut merupakan antisipasi dan jawaban terhadap realitas sosial

${ }^{14}$ Naskah Piagam Madinah tersebut tertera dalam Ibn Hisyam, op.cit, h. 301-303, Muhammad Husein Haikal, Hayat Muhammad (Sejarah Hidup Muhammad), terj. Ali Audah, (Jakarta: Litera Antarnusa, 1990), h. 2000-2002, Ibn Ishaq, Sirah Rasulillah, tej. Edisi Inggeris oleh A. Guillaume, The Life of Muhammad, (Oxford: Oxford University, 1970), h.231-233. Lihat juga dalam: Abu Ubaid, Kitab alAmwal, (Beirut: Dar al-Fikr, 1988),h. 260-264, Ibn Katsir, al-Bidayah wa al-Nihayah, (Beirut: Dar al-Fikr, 1978), j.III, h. 244-246, John Williams (ed.), Themes of Islamic Civilization, (California: University of California Press, 1971), h.12-15.

${ }^{15}$ Ahmad Ibrahim Syarif, Daulah al-Rasul fi al-Madinah, (Kuwait: Dar al-Bayan, 1972), h.89. Lihat juga: Zainal Abidin Ahmad, Konsepsi Politik dan Ideologi Islam, (Jakarta: Bulan Bintang, 1977), h.170-172. masyarakat Madinah yang plural. Secara strategis, piagam ini bertujuan untuk menciptakan keserasian politik dengan mengembangkan toleransi sosioreligius dan budaya seluas-luasnya. ${ }^{16}$

Tujuan Nabi untuk mengatur masyarakat Madinah ialah untuk menetralisir kekuasaan kelompok-kelompok sosial yang ada yang sering terjerumus kepada konflik, dan membimbing mereka kepada suasana kebersamaan. Sisi ini ditinjau dari ilmu politik, langkah ini menunjukkan bahwa Nabi telah melaksanakan kekuasaan politik, seperti yang dimiliki oleh suatu negara, yang bertujuan untuk mengatur hubungan-hubungan manusia dalam masyarakat, mengontrol dan menertibkan unsur-unsur atau gejala-gejala kekuasaan dalam masyarakat. Memang, manusia di samping hidup dalam kerjasama antagonis, kadang penuh konflik dan persaingan. Pengaturan hubungan-hubungan tersebut, walaupun ada unsur pemaksaan adalah untuk menetapkan tujuan-tujuan kehidupan bersama. ${ }^{17}$

Atas dasar itu, Pickthal menilai kelahiran dan fungsi naskah Piagam Madinah itu menjadi bukti bahwa Nabi menampilkan diri sebagai sosok pemimpin untuk menetapkan dan mengatur kepentingan umum sebagai undang-undang negara. ${ }^{18}$

Dengan demikian, pembentukan negara dalam sejarah Islam dimulai ketika Nabi mengatur masyarakat Madinah secara konstitusional setelah hijrah dari Mekah ke Madinah. Sistem yang dibangun oleh Rasulullah di Madinah itu, menurut ilmu politik modern, sudah memenuhi syarat-syarat nominal untuk disebut sebagai negara, yaitu adanya penduduk, wilayah, pemerintahan, dan kedaulatan. ${ }^{19}$

G.A. Jacobsen dan M.H. Lipman menegaskan:

Negara modern diartikan sebagai lembaga politik yang terorganisasi daripada orang-orang/

${ }^{16}$ A. Syafi'i Ma'arif, " Piagam Madinah dan Konvergensi Sosial," dalam Islam dan Politik di Indonesia pada Demokrasi Terpimpin (1959-1965), (Yogyakarta: IAIN Sunan Kalijaga Press, 1988), apendiks II, h. 149-164.

${ }^{17}$ Miriam Budiardjo, Op.Cit., h. 35-38.

${ }^{18}$ Muhammad Marmaduke Pickthal, The Meaning of Glorious Koran, (New York: New American Library, 1953), h. xvii.

${ }^{19}$ Miriam Budiardjo, Op.Cit., h. 42-44, Wirjono Prodjodikoro, Asas-asas Ilmu Negara dan Politik, (Bandung: PT Eresco, 1981), h.13, dan M.Solly Lubis, Ilmu Negara, (Medan: Mandar Maju, 1990), h. 2. 
rakyat, atau yang mempunyai daerah teritorial tertentu serta hidup di bawah pemerintahan yang seluruhnya atau hampir seluruhnya merdeka-bebas daripada kontrol dari luar dan sanggup memelihara ketaatan daripada semua yang di dalamnya. ${ }^{20}$

Defenisi lain tentang negara adalah "sekelompok orang yang menetap di suatu daerah tertentu yang diorganisir secara politik di bawah suatu pemerintahan yang berdaulat dan bebas dari pengawasan luar dan memiliki kekuasaan memaksa untuk mempertahankan keteraturan dalam masyarakat.”21 Menurut Robert M. Mac Iver, "Negara adalah suatu asosiasi dalam suatu teritori untuk menyelenggarakan ketertiban masyarakat berdasarkan sistem hukum yang diselenggarakan oleh pemerintah yang memiliki kebebasan memaksa (the state is an association which, acting through law as promulgated by a government within a community territorially demarcated the external conditions of order)". ${ }^{22}$ Atas dasar itu, negara adalah sekelompok orang-orang yang terorganisir, menetap di wilayah tertentu yang mempunyai kedaulatan dan kebebasan untuk mewujudkan ketertiban masyarakat dan menentukan tujuannya di bawah suatu pemerintahan.

Adapun unsur-unsur penting terbentuknya suatu negara, terdiri dari wilayah, yaitu Madinah; rakyat yang terdiri dari golongan-golongan Muslim dan non-Muslim; pemerintahan yang dipegang oleh Nabi dan dibantu oleh para sahabatnya; dan berdaulat yang berdasarkan pada undang-undang tertulis sebagai "kesepakatan antar golongan untuk membangun masyarakat politik bersama”, ${ }^{23}$

${ }^{20}$ G.A.Jacobsen dan M.H. Lipman, Political Science, (New York: 1960), h. 29.

${ }_{21}$ Philip Babcock Gove, et.al., (eds), Webster's Third New International Dictionary of the English Language, (Massachusets: G \& G Merriam Company, 1961), h.2228

22 Robert M. Mac Iver, The Modern State, (London: Oxford University Press, 1955), h.22.

${ }^{23}$ Nurcholis Madjid, “Cita-cita Politik Kita” dalam Basco Carvalo and Dasrizal (eds), Aspirasi Umat Islam Indonesia, (Jakarta: Leppenas, 1983), h. 11. Sehubungan dengan keberadaan Negara Madinah, Fathi Ostman, penulis buku "Adhwa 'ala al-Tarikh al-Islamy” menegaskan bahwa berabad-abad sebelum Jean Jacques Rouseau mengemukakan teori “Kesepakatan Sosial”-nya (The Social Contract), sebenarnya Nabi Muhammad telah mempraktekkan perjanjian masyarakat itu untuk menegakkan negara Islam. (Lihat: Adhwa 'ala al-Tarikh al-Islamy, Kairo: Dar al-Kutub, 1956), h. 99-100.
Mengacu pada pemikiran-pemikiran di atas, dapat ditegaskan bahwa Madinah merupakan wilayah kekuasaan yang secara langsung dipimpin oleh Nabi Muhammad saw sebagai kepala negara yang mempunyai kedaulatan dalam mengatur rakyatnya, yaitu masyarakat Muslim di Madinah (kaum Muhajirin dan Anshar), dan kaum Yahudi yang mempunyai suku-suku yang beragam. Kelompok-kelompok yang beragam ini, agar menjalin suasana damai dan kerjasama diatur secara mendasar dalam Piagam Madinah tersebut.

\section{Prinsip-prinsip Negara dalam Syariah Islam}

Menurut teori Islam, negara yang dibentuk seyogianya mengacu pada prinsip-prinsip syari'ah. Artinya, nilai-nilai syari'ah direalisir dalam kehidupan berbangsa dan bernegara. ${ }^{24}$

Endang Saifuddin Anshari mengatakan:

Negara adalah organisasi (organ, badan atau alat) bangsa untuk mencapai tujuannya... Bagi setiap Muslim negara adalah alat untuk merealisasikan kedudukannya sebagai abdi Allah dan mengaktualisasikan fungsinya sebagai khalifah Allah, untuk mencapai keridhaan Allah, kesejahteraan duniawi dan ukhrawi, serta menjadi rahmat bagi sesama manusia dan alam lingkungannya. ${ }^{25}$

Karena itu, secara tradisional, para ahli fikih menekankan tiga ciri penting sebuah negara Islam itu: masyarakat Muslim (ummah), hukum Islam (syari'ah), dan kepemimpinan masyarakat Muslim (khalifah). ${ }^{26}$

Prinsip-prinsip negara dalam Islam tersebut ada yang berupa prinsip-prinsip dasar yang mengacu pada teks-teks syari'ah yang jelas dan tegas. Selain itu, ada prinsip-prinsip tambahan yang merupakan kesimpulan dan termasuk ke dalam fikih. ${ }^{27}$

Prinsip-prinsip dasar tersebut adalah: pertama, kedaulatan. Kedaulatan yang mutlak dan legal

${ }^{24}$ S. Waqar Ahmed Husaini, Islamic Evironmental System Engineering, (London: The Macmillan Press,1980), Cet Ke-1, h. 93.

${ }^{25}$ Endang Saifuddin Anshari, Wawasan Islam, (Jakarta: Rajawali Press, 1986), h. 167.

${ }^{26}$ Mumtaz Ahmad, State, Politics, and Islam, alih bahasa Ena Hadi, Masalah-masalah Teori Politik Islam, (Bandung: Mizan, 1994), h.58.

${ }^{27}$ S. Waqar Ahmed Husaini, Op.Cit., h. 93-95. 
adalah milik Allah. Abu al-A'la al-Maududi menyebutnya dengan "asas pertama dalam teori politik Islam.” Al-Maududi menegaskan:

Kepercayaan terhadap keesaan (tauhid) dan kedaulatan Allah adalah landasan dari sistem sosial dan moral yang dibawa oleh Rasul Allah. Kepercayaan itulah yang merupakan satusatrunya titik awal dari filsafat politik dalam Islam. ${ }^{28}$

Kedaulatan ini terletak di dalam kehendak-Nya seperti yang dapat dipahami dari syari'ah. Syari'ah sebagai sumber dan kedaulatan yang aktual dan konstitusi ideal, tidak boleh dilanggar. Sedang masyarakat Muslim, yang diwakili oleh konsensus rakyat (ijma' al-ummah), memiliki kedaulatan dan hak untuk mengatur diri sendiri.

Kedua, syura dan ijma'. ${ }^{29}$ Mengambil keputusan di dalam semua urusan kemasyarakatan dilakukan melalui konsensus dan konsultasi dengan semua pihak. Kepemimpinan negara dan pemerintahan harus ditegakkan berdasarkan persetujuan rakyat melalui pemilihan. Sebuah pemerintahan atau sebuah otoritas (sulthan) yang ditegakkan dengan cara-cara non-syari'ah adalah tidak sah dan tidak dapat memaksa ketaatan rakyat.

Ketiga, semua warga negara dijamin hak-hak pokok tertentu. Di antaranya adalah: jaminan terhadap keamanan pribadi, harta benda dan harga diri, kemerdekaan untuk mengeluarkan pendapat dan berkumpul, hak untuk mendapatkan pelayanan hukum secara adil tanpa diskriminasi, hak untuk mendapatkan pendidikan yang layak, pelayanan medis dan kesehatan, serta keamanan untuk melakukan aktifitas-aktifitas ekonomi. ${ }^{30}$

Keempat, hak-hak negara. Semua warga negara yang bertentangan pendapat dengan pemerintah sekali pun, mesti tunduk kepada otoritas negara

${ }^{28}$ Abu al-A'la al-Maududi, It's Meaning and Message, peny. Khurshid Ahmad, (London: Islamic Council of Europe, 1976), h. 147-148 dan The Islamic Law and Constitution, terj. Asep Hikmat, Hukum dan Konstitusi, Sistem Politik Islam, (Bandung: Mizan, 1990), Cet.ke-1, h. 156-157.

${ }^{29}$ M.Yusuf Musa, Politik dan Negara dalam Islam, (Surabaya: Al-Ikhlas, 1970), h. 182-184.

30 Subhi Mahmassani, Arkan Huquq al-Insan, alih bahasa Hasanuddin, Konsep Dasar Hak-hak Asasi Manusia, Studi Perbandingan Syari'ah Islam dan Perundang-undangan Modern, (Jakarta: Tintamas Indonesia-Pustaka Litera Antar Nusa, 1993), h. 73-164. yaitu kepada hukum-hukum negara. ${ }^{31}$

Kelima, hak-hak khusus dan batasan-batasan bagi warga negara yang non-Muslim-memiliki hak-hak sipil yang sama. ${ }^{32}$ Karena negara ketika itu adalah negara ideologis, maka tokoh-tokoh pengambilan keputusan yang memiliki posisi kepemimpinan dan otoritas (ulu al-amr), mereka harus sanggup menjunjung tinggi syariah. Dalam sejarah politik Islam, prinsip dan kerangka kerja konstitusional pemerintahan seperti ini, terungkap dalam Konstitusi Madinah atau "Piagam Madinah" tersebut.

Keenam, ikhtilaf dan konsensus yang menentukan. Perbedaan-perbedaan pendapat harus diselesaikan berdasarkan keputusan dari suara mayoritas yang harus ditaati oleh seluruh masyarakat. Prinsip mengambil keputusan menurut suara mayoritas ini sangat penting untuk mencapai tujuan bersama. ${ }^{33}$

Selain prinsip-prinsip dasar negara yang konstitusinya berdasar syariah, ada juga prinsipprinsip tambahan (subsider) yang merupakan kesimpulan dan termasuk ke dalam bidang fikih dari hukum Islam. Prinsip-prinsip tambahan tersebut adalah mengenai pembagian fungsi-fungsi pemerintahan yaitu hubungan antara Badan Legislatif, Eksekutif, dan Yudikatif. Dalam hubungan ketiga badan (lembaga negara) tersebut, prinsipprinsip berkonsultasi (syura) harus dilaksanakan di dalam riset, perencanaan, menciptakan undangundang dan menjaga nilai-nilai syariah dengan memperhatikan otoritas (kewenangan) yang dimiliki masing-masing lembaga tersebut. ${ }^{34}$

Prinsip-prinsip pembentukan negara dalam syariah, Abdul Qadir Audah menyebutnya dengan prinsip-prinsip politik ajaran Islam. Menurutnya,

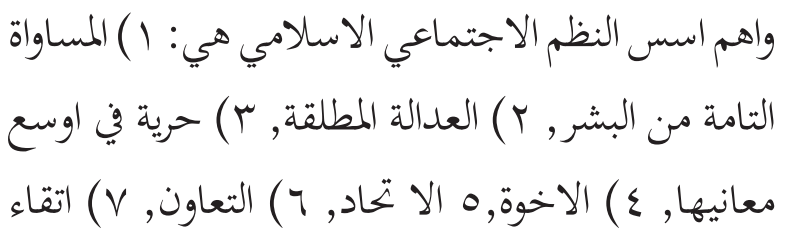

${ }^{31}$ Ibid., h. 66

${ }^{32}$ Ibid., h. 55-61.

${ }^{33}$ S. Waqar Ahmed Husaini, Op.Cit., h. 93-95.

${ }^{34}$ Ibid, h. 95-96. 


$$
\begin{aligned}
& \text { المحارج, ^) التحلي بالفضائل, 9 ) الاستخلاف في ملك } \\
& \text { الله, • (1) تفتيت الثروات, (1) البر والتراحم, r (1) } \\
& \text { الاستمساك بالشوري. }
\end{aligned}
$$

(Prinsip-prinsip politik dalam ajaran Islam itu adalah: 1) Persamaan yang komplit; 2) Keadilan yang merata; 3) Kemerdekaan dalam penegrtian yang sangat luas; 4) Persaudaraan; 5) Persatuan; 6) Gotong royong (saling membantu); 7) Membasmi pelanggaran hukum; 8) Menyebarkan sifat-sifat utama; 9) Menerima dan mempergunakan hak milik yang dianugerahkan Tuhan; 10) Meratakan kekayaan kepada seluruh rakyat, tidak boleh menimbunnya; 11)Berbuat kebajikan dan saling menyantuni; 12) Memegang teguh prinsip musyawarah). ${ }^{35}$

Adapun menurut M. Tahir Azhary, di dalam Alquran dan Sunnah Rasulullah terkandung sembilan prinsip negara hukum, yakni:

(1) Prinsip kekuasaan sebagai amanah (QS. 4: 58, 14-13); (2) Prinsip musyawarah (42: 38, 3: 159); (3) Prinsip keadilan (4:135, 5:8, 16:90, 6:160); (4) Prinsip persamaan (9:13); (5) Prinsip pengakuan dan perlindungan terhadap hak-hak asasi manusia (17: 70, 17: 33, 5: 32, 88: 21, 88 : 22, 50: 45, 4: 32); (6) Prinsip pengadilan bebas (dialog Mu'adz dengan Rasulullah saw ketika akan diangkat menjadi hakim di Yaman); (7) Prinsip perdamaian (2: 194, 2: 190, 8: 61 -62); (8) Prinsip kesejahteraan (34: 15); (9) Prinsip ketaatan rakyat (4: 59). ${ }^{36}$

Sebenarnya masih banyak para pakar politik dan hukum Islam yang menguraikan prinsipprinsip negara dalam syariat Islam. Namun dari uraian di atas cukup representatif bagi penulis untuk menyimpulkan bahwa prinsip-prinsip negara dalam Islam itu adalah: 1) prinsip tauhid; 2) prinsip keadilan; 3) prinsip kedaulatan rakyat; 4) prinsip musyawarah; 5) prinsip kesamaan di hadapan hukum; 6) prinsip kebebasan rakyat; 7) prinsip persatuan; 8) prinsip persaudaraan; 9)

\footnotetext{
${ }^{35}$ Abdul Qadir Audah, Al-A'mal al-Kamilah: Al-Islam wa Audha'una al-Qanuniyah, (Kairo: al-Mukhtar al-Islamy, 1994), h. 211-223.

${ }^{36}$ Muhammad Tahir Azhary, Negara Hukum, Suatu Studi tentang Prinsip-prinsipnya Dilihat dari Segi Hukum Islam, Implementasi Pada Periode Madinah dan Masa Kini, (Jakarta: Bulan Bintang, 1992), h. 27.
}

prinsip kekuasaan sebagai amanah; 10) prinsip ketaatan rakyat; 11) prinsip perdamaian; 12) prinsip kesejahteraan; 13) prinsip pengakuan dan perlindungan terhadap hak-hak asasi manusia.

Setelah diteliti dan dikaji, ternyata keberadaan Negara Madinah sarat dengan prinsip-prinsip ini. Dalam Piagam Madinah, misalnya, digalang suatu perjanjian untuk menetapkan persamaan hak dan kewajiban semua komunitas dalam kehidupan sosial politik. Muatan piagam ini menggambarkan hubungan antara Islam dan ketatanegaraan dan undang-undang yang diletakkan oleh Nabi saw, untuk menata kehidupan sosial-politik masyarakat Madinah.

Prinsip-prinsip negara tersebut sangat representatif untuk masa itu. Bahkan untuk dewasa ini pun relevan karena nilai-nilainya universal. Sebab prinsip-prinsip tersebut telah menjadi tuntunan berbagai bangsa di dunia, agar tegak dalam hidup bermasyarakat dan bernegara, yaitu tatanan masyarakat yang demokratis, adil, dan damai. Karena pada hakikatnya implementasi prinsipprinsip tersebut merupakan penghargaan terhadap hak-hak asasi manusia, dan akan menumbuhkan sikap demokratis dalam berbagai aspek kehidupan.

\section{Penutup}

Dalam teori politik Islam diletakkan prinsipprinsip dasar politik kenegaraan. Prinsip-prinsip politik tersebut, misalnya penegakkan keadilan, perlindungan HAM, mengejawantah pada periode Madinah. Sejarah menunjukkan keberadaan negara Madinah itu juga menjadi bukti-bukti bagi terpenuhinya syarat-syarat nominal untuk disebut sebagai suatu "negara".

Unsur-unsur penting bagi terbentuknya Negara Madinah, dapat dikemukakan terdiri dari adanya wilayah, yaitu Madinah; rakyat yang terdiri dari golongan-golongan Muslim dan non-Muslim; pemerintahan dikendalikan oleh Nabi saw dan dibantu oleh para sahabatnya; serta berdaulat yang berdasarkan pada undang-undang tertulis (Piagam Madinah) dalam komunitas masyarakat Madinah tersebut. 


\section{Pustaka Acuan}

Arnold, Thomas W., The Caliphate. London: Routledge and Kegan Paul, Ltd., 1965

Asad, Muhammad, The Principles of State and Government in Islam. Berkeley and Los Angeles: University of California Press, 1961.

Audah, Abdul Qadir, Al-A'mal al-Kamilah, Al-Qanun wa Audha'una al-Siyasah. Kairo: Al Mukhtar al- Islamy, 1994.

Azra, Azyumardi, and Arskal Salim (ed.), "Introduction, The State and Shari'a in the Perspective of Indonesian Legal Politics," dalam Shari'a and Politics in Modern Indonesia. Singapore: Institute of Southeast Asian Studies, 2003.

Benson, Purnell Handy, Religion in Contemporary Culture. New York: Harper and Brothers, 1960.

Effendy, Bahtiar, Islam dan Negara, Transformasi Pemikiran dan Praktik Politik Islam di Indonesia. Jakarta: Paramadina, 1998.

Efrinaldi, Fiqh Siyasah, Dasar-dasar Pemikiran Politik Islam. Jakarta: Granada Press, 2007.

Efrinaldi, Rekonstruksi Pemikiran Politik Islam. Jakarta: Citra Publika Press, 2008.

Efrinaldi, Teori Pembentukan Negara, Visi alGhazali (Merajut Etika dalam Transisi Politik dan Kekuasaan). Jakarta: Transmisi Media, 2002.

Emerson, Rupert, "The Erosion of Democracy”, The Journal of Asian Studies, Vol. XX, No.1, November 1960, dalam Alvin Z. Rubinstein dan Garold W.Thumm (ed.), The Challenge of Politics, Ideas and Issues. Toronto: Prentice-Hall of Canada Ltd., 1965.

Faris, Muhammad Abdul Qadir Abu, Al-Nizham alSiyasi fi Al-Islam. Yordania: Darul Furqan, 1986.

Flechtheim, Ossip K., Fundamentals of Political Science. New York: Ronald Press Co., 1952

Hamid, Tijani Abdul Qadir, Ushul al-Fikr al-Siyasi fi al-Qur'an al-Makki, terj. Abdul Hayyie al-Kattani, Pemikiran Politik dalam al-Qur'an. Jakarta; Gema Insani Press, 2001.

Hasan Ibrahim Hasan, Tarikh al-Islam al-Siyasy wa al-ainy wa-alTsaqafy wa al-Ijtima’i (Kairo: Maktabah al-Nahdhah al-Mishriyah, 1967).
Hatta, Mohammad, Islam, Society, Democracy and Peace. New Delhi: Information Service Indonesia, Embassy of the Republic of Indonesia, 1955.

Hitti, Philip K., History of the Arabs, London: The Macmillan Press Ltd., 1974.

Holt, P.M., The Cambridge History of Islam, vol 2 A. London: Cambridge University Press, 1984.

Hodgson, Marshall G.S. The Venture of Islam: Conscience and History in a World of Civilization, Volume I-III, Chicago: University of Chicago Press, 1974.

Husaini, S. Waqar Ahmed. Islamic Evironmental System Engineering. London: The Macmillan Press,1980

Ibn Taimiyah, Taqy al-Din Abu al-Abbas Ahmad, Al-Siyasah al-Syar'iyah fi Ishlah al-Ra'i wa alRa'iyah. Maroko: Dar al-Afaq al-Jadidah, 1991.

Ibn al-Atsir, al-Kamil fi al-Tarikh, jilid 10. Beirut: Dar al-Shadir, 1966.

Ibn al-Rabi', Suluk al-Malik fi Tadbir al-Mamalik. Kairo: $1286 \mathrm{H}$.

Mawardi, Al-Ahkam al-Sulthaniyah. Beirut: Dar al-Fikr, 1989.

Moten, Abdul Rashid, Political Science: An Islamic Perspective, terj. Munir A. Mu'in dan Widyawati, Ilmu Politik Islam. Bandung: Pustaka, 2001

Rahman, Fazlur, Islam and Modernity: Transformation of an Intellectual Tradition. Chicago: Chicago University Press, 1980.

Sabine, George, A History of Political Theory. New York: Henry Holt and Company, 1954.

Uhlin, Anders, Indonesia and the "Third Wave of Democratization":The Indonesian Pro-Democracy Movement in a Changing World. London: Nordic Institute of Asian Studies, Richmond, Curzon Press, 1997.

Vatikiotis, P.J., Islam and The State. London and New York: Routledge, 1987.

Watt, W. Montgomery, Islamic Political Thought. Edinburgh: Edinburgh University Press, 1960. 